\title{
Experimental Study on the Low-velocity Impact Behavior of Foam-core Sandwich Panels
}

\author{
Jie Wang * \\ Shanghai Jiao Tong University, Shanghai, 200240, China \\ Anthony M. Waas ${ }^{\dagger}$ \\ University of Michigan, Ann Arbor, Michigan, 48109, USA \\ Hai Wang $\ddagger$ \\ Shanghai Jiao Tong University, Shanghai, 200240, China
}

\begin{abstract}
This paper presents the results of an experimental study on the low-velocity impact behavior of foam-core sandwich panels. Panels with PUR foam core and plain weave carbon fabric laminated face-sheets were subjected to low-velocity impact with hemispherical steel impactors of different diameters at various energy levels. Digital image correlation (DIC) technique (ARAMIS software) was used to measure the real-time displacement and velocity of the impactor, and the back surface out-of-plane panel deflection time-history. A load sensor was used to record the contact force time-history. Non-destructive inspection (NDI) and destructive sectioning methods were used to evaluate the internal and external damage on the sandwich panels after impact. The effects of impact variables such as impactor diameter, impact energy, and sandwich panel configuration parameters, such as face-sheet thickness and foam core thickness on the impact behavior and resulting impact damage states were studied.
\end{abstract}

\section{Introduction}

SANDWICH structures have been widely used in a variety of applications including aircraft structures and Satellite launch vehicles, as well as in structures in the automotive and sporting goods industry. This is due to their superior performance in comparison to other structural materials in terms of improved stability, high stiffness and strength to weight ratios, and ease of manufacture and repair ${ }^{1,2}$. However, sandwich panels are susceptible and vulnerable to foreign object impact, especially low-velocity impact. For aircraft structures, such impact may be caused by tool drop during maintenance, hail strike in service or objects thrown up from the runway during landing and take off; for naval structures, a wider range of low-velocity (quasi-static) impact may occur due to the complicated environment they have to encounter. The damage caused by low-velocity impact may significantly reduce the stiffness and residual strength of the composite ${ }^{1}$. For this reason, a significant amount of work has been done by different researchers to address the problem of low-velocity impact on sandwich structures ${ }^{1-3}$. The previous work can be classified into 3 categories: 1 ) impact response study; 2) damage characterization; 3) parametric studies on post-impact and impact event. A brief review of these three types of study are given next.

The mechanical response of low-velocity impact on sandwich structures have been extensively studied using experimental, numerical and analytical methods. Many researchers have conducted impact tests on sandwich panels composed of different face-sheets and core materials. The mechanical response of the panels was recorded and analyzed in terms of peak load, absorbed energy, and deflection at peak load ${ }^{4-9}$. In particular, Mines et al. ${ }^{10}$ tested sandwich panels made from woven glass vinyl ester skins with Coremat core and woven glass epoxy pre-preg skins with honeycomb core. Their results indicate that the energy absorbing

\footnotetext{
${ }^{*}$ Graduate Student, School of Aeronautics and Astronautics, and visiting student, Department of Aerospace Engineering, University of Michigan, Ann Arbor.

${ }^{\dagger}$ Felix Pawlowski Collegiate Professor, Department of Aerospace Engineering. Fellow, AIAA.

${ }_{\ddagger}^{\ddagger}$ Professor, School of Aeronautics and Astronautics.
} 
capabilities of the panels increase with the velocity of impact and this is due to an increase in the core crush stress and skin failure stress at high strain rates. Bhuiyan et al. ${ }^{5}$ experimentally characterized the peak load, absorbed energy, and the deflection at peak load (including time-history) during the impact.

The finite element method (FEM) has been used to simulate the mechanical response of low-velocity impact ${ }^{10-13}$. In particular, Karger et al. ${ }^{14}$ used three-layered shell elements combined with macro-mechanical damage models to simulate the impact behavior of sandwich structures consisting of two composite facesheets and a compliant core. Aminanda et al. ${ }^{15,16}$ simulated the low-velocity impact on Nomex honeycomb sandwich structures with metallic skins, where the sandwich structure is modeled by Mindlin plate elements and the computed static contact law is implemented in a nonlinear spring located between the impactor and the structure.

A comprehensive review of analytical models has been given by Abrate ${ }^{17}$, classifying the previous studies into three categories: 1) energy-balance models that assume a quasi-static behavior of the structure; 2) spring-mass models that account for the dynamics of the structure in a simplified manner; 3) complete models in which the dynamic behavior of the structure is fully modeled. New progress ${ }^{18-20}$ has been made for analytically investigating the impact response of sandwich structures.

The effects of impact parameters such as impactor diameter, impact velocity, impact energy and sandwich construction parameters such as core material and thickness, and face-sheet type on the impact behavior are also of major concerns in many studies. Etemadi et al. ${ }^{21}$ studied the effects of projectile initial velocity and kinetic energy, as well as the sandwich beam's dimensions on the impact behavior and indentation and displacement history by 3D finite element method. According to the study by Raju et al. ${ }^{22}$, the impact response of flat $[(0 / 45) \mathrm{n} / \mathrm{core} /(45 / 0) \mathrm{n}]$ sandwich plates with a honeycomb core, characterized in terms of peak impact force was observed to be dependent on the face-sheet type, core thickness, and impactor size, but was found to be independent of the boundary support conditions. Recently, Lascoup et al. ${ }^{23}$ investigated the impact response of three-dimensional stitched sandwich composites, and the effects of stitching, stitching step and stitching angle on impact load, displacement and impact energy.

Extensive delamination and core damage can be caused by low-velocity impact on sandwich structures, with no visible surface damage ${ }^{24}$. For this reason, non-destructive inspection (NDI) and destructive methods have been used to characterize the damage type and extent on impacted sandwich panels. Ultrasonic Cscan and X-ray imaging are the common methods for detecting the face-sheet (composite mainly) and core damage underneath the impact area. Sectioning methods, combined with optical and scanning electron microscopy ${ }^{4,5,9,25}$ have been used to evaluate the damage area and failure patterns around the impacted area, within the panel.

Traditionally, the face-sheets of sandwich structures are made of unidirectional laminates or metal sheets, while the core materials are aluminum or Nomex honeycombs. Most of the work reviewed above pertain to this type of sandwich structure. In recent years, sandwich panels with plain weave laminated face-sheets and closed-cell foam cores are becoming prevalent, because plain weave fabrics have balanced ply properties and improved inter-laminar properties compared to unidirectional laminates, and high stiffness and strength to weight ratios compared to metal sheets; meanwhile, high performance closed-cell foams can significantly improve the performance of sandwich structures with their superior environmental properties such as water resistance, and sound insulation. Much remains to be investigated with respect to deformation response and failure of such composites.

In this paper, a comprehensive study on the low-velocity impact behavior of foam-core sandwich panels with plain weave laminated face-sheets, is reported. The mechanical response of low-velocity impacted sandwich panels will be characterized in terms of peak force, absorbed energy/impact energy ratio and contact duration, while obtaining deformation time histories; both non-destructive inspection and sectioning methods will be used to evaluate localized damage such as face-sheet indentation, fiber breaks, matrix cracking, and core crushing induced by impact event. The damage process during the impact event was reconstructed by analyzing the characteristics of contact force-impactor displacement curves and corresponding sectioning images of damaged specimens. The effects of impactor size, impact energy, face-sheet thickness, and core thickness on the impact response and resulting impact damage states were also studied.

\section{Materials and specimen}

The sandwich panels considered in this study consist of composite laminate face-sheets and a foam core. The face-sheets are laminates made of T300B 3K plain weave carbon fabrics. Two stacking sequences 
(thicknesses) are considered for the laminated face-sheets in this study: $[0 / 90]_{4}(1 \mathrm{~mm}$ in thickness) and $[0 / 90]_{8}$ (2mm in thickness). Polyurethane (PUR) foam is used as the core material.

The Last-A-Foam FR-series closed-cell polyurethane foam was supplied by General Plastics Manufacturing Company. The foam core for the sandwich panels were made into two thicknesses: $12.5 \mathrm{~mm}$ and $25 \mathrm{~mm}$.

The sandwich panels were constructed at the University of Utah using a vacuum assisted resin transfer molding (VARTM) process. The panels were cut into specimens of $100 \mathrm{~mm} \times 150 \mathrm{~mm}$ using a milling machine with a diamond coated blade. Face-sheet laminates were removed from the sandwich panels for standard mechanical tests. The properties of the foams and the face-sheet plies measured by standard test will be shown in the second part of this study.

\section{Drop-weight impact tests}

Low-velocity impact tests with a range of energies were performed with a drop weight instrumented impact tower, as shown in Fig.1(a). The energy levels were varied by altering the drop height of the impact carriage. Load history of each impact event was measured by a KISTLER force transducer located between the impactor and the dropped carriage. A high speed oscilloscope was used to acquire and record the data during the impact.

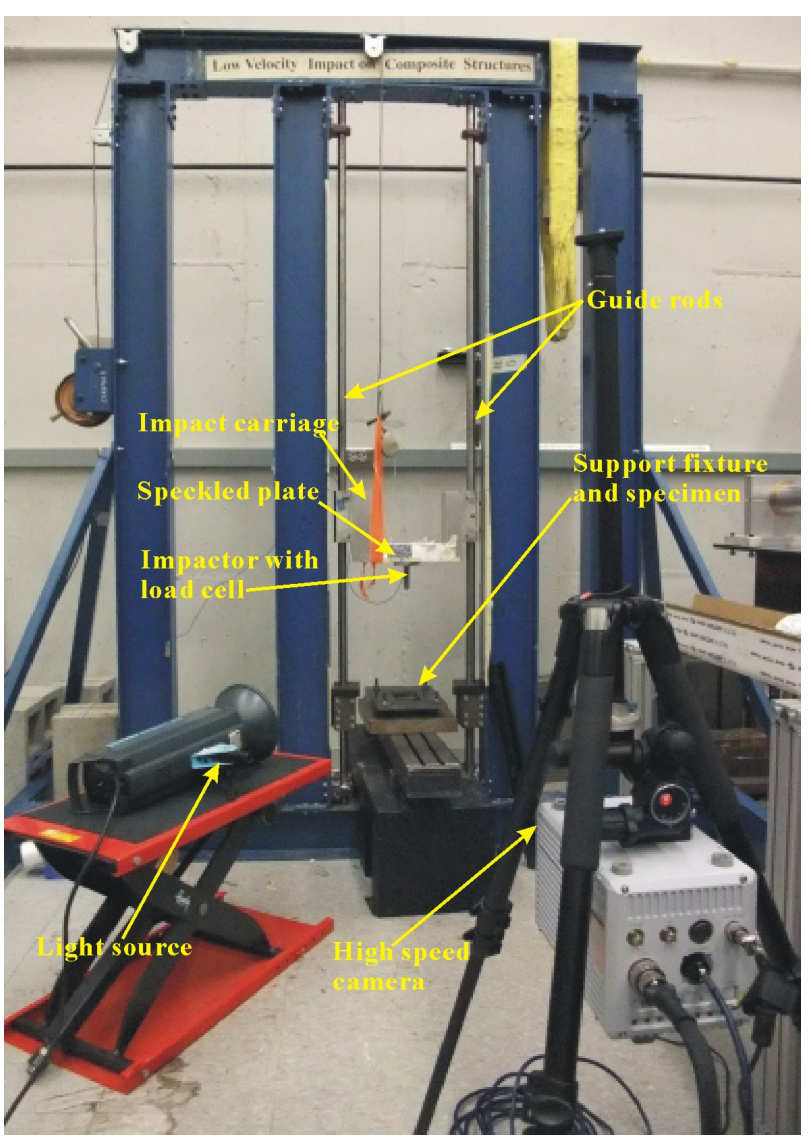

(a)

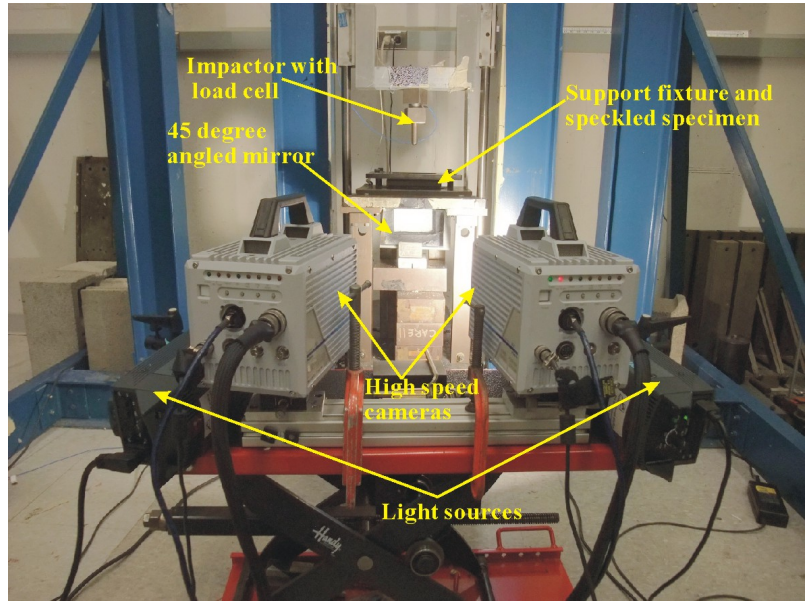

(b)

Figure 1: Setups for impact test: (a) setup-1; (b) setup-2.

The test specimens are positioned in a support fixture composed of two steel plates, with a rectangular window cut-out of $75 \mathrm{~mm} \times 125 \mathrm{~mm}$ in the center of the plates. The specimens were simply-supported between the two plates by 4 steel rods of $6 \mathrm{~mm}$ in diameter positioned along the perimeter of the test section. The

We are grateful to Prof. Dan Adams and Bradley Kenji Kuramoto for manufacturing the sandwich panels. 
specimens were secured between the two plates by 4 fasteners as shown in Fig. 2 .

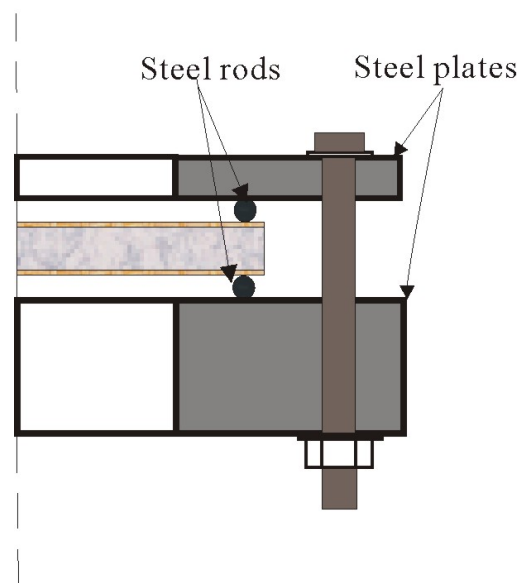

Side view

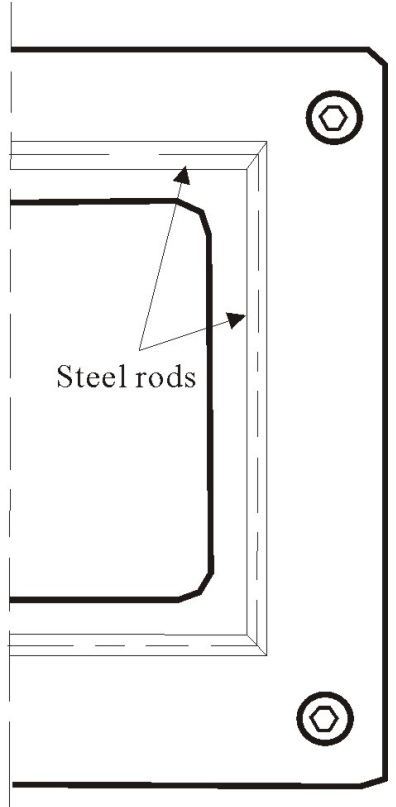

Top view

Figure 2: Support fixture for the impact test.

The sandwich specimens were impacted at the center of the test section by hemispherical steel impactor of three different diameters. Two setups were built for the impact tests. In the first setup, the impact velocity and displacement, during the impact, were determined by using the ARAMIS system and a high speed camera. As shown in Fig.1(a), a well speckled (fine white and black dots in a random pattern) plate was put on the impact carriage right above the impactor. A high speed camera was mounted at a certain distance facing the speckled plate where the impactor begin to contact the specimen. The camera and the oscilloscope were synchronized by connecting to a trigger which used the signal from the force transducer as input (trigger value). The camera took pictures at a constant sampling frequency of $20 \mathrm{kHz}$. (The camera was set to record some images before the trigger point. These images can be used to obtain the velocity of the impactor at the instant when the impactor touched the specimen). The images were analyzed using the ARAMIS software. Based on these images, the ARAMIS software can identify points on the surface of the speckled plate and divide it into facets, and coordinates were assigned to the facets for following their displacements. An area to be evaluated will be defined (computation mask) on all the images, and a start point will be determined prior to computation. After computation, the ARAMIS system can extract the displacement and velocity of the image during impact, which should be the same as the impactor's displacement and velocity. In the second setup, a $45^{\circ}$ angled mirror was placed below the impacted plate in conjunction with 2 high speed cameras to obtain the panels back surface out-of-plane deflection time-history, as shown in Fig.1(b).

Table 1: Sandwich configurations and test matrix for impact

\begin{tabular}{lllllll}
\hline $\begin{array}{l}\text { Face-sheet } \\
\text { material }\end{array}$ & $\begin{array}{l}\text { Core ma- } \\
\text { terial }\end{array}$ & $\begin{array}{l}\text { Stacking } \\
\text { sequence }\end{array}$ & $\begin{array}{l}\text { Face-sheet } \\
\text { thickness } \\
(\mathrm{mm})\end{array}$ & $\begin{array}{l}\text { Core thick- } \\
\text { ness }(\mathrm{mm})\end{array}$ & $\begin{array}{l}\text { Impactor } \\
\text { diameter } \\
(\mathrm{mm})\end{array}$ & $\begin{array}{l}\text { Impact en- } \\
\text { ergy }(\mathrm{J})\end{array}$ \\
\hline T300B 3K/ & \multirow{2}{*}{ PUR } & {$[0 / 90]_{4}$} & 1.0 & $12.5,25$ & 15,25 & 30 \\
EPON 862 & & {$[0 / 90]_{8}$} & 2.0 & $12.5,25$ & $15,25,35$ & $7.5,15,30$ \\
\hline
\end{tabular}




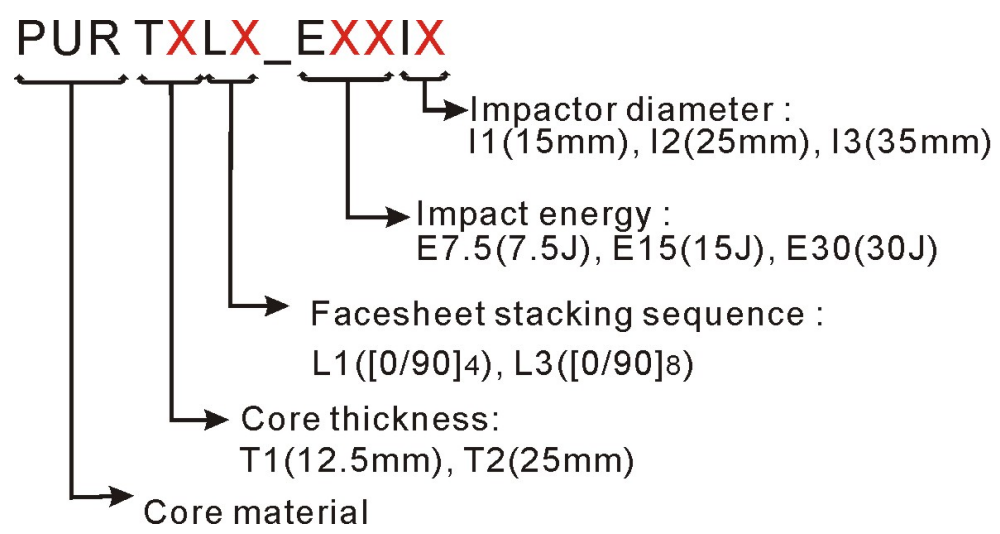

Figure 3: Coding for the tested cases.

The impact test matrix used in the investigation is summarized in Table 1. Two sandwich construction parameters were considered; face-sheet configuration/thickness and core thickness. Impactor diameter and impact energy were the two impact variables. The changeable hemi-spherical steel rods with diameters of $15 \mathrm{~mm}, 25 \mathrm{~mm}$ and $35 \mathrm{~mm}$ were used as impactors. The coding for the test cases is shown in Fig. 3. For each case, at least 3 specimens were tested. The cases coding will be referenced for discussing the test results in the following sections.

\section{Damage characterization}

During the low-velocity impact event, all three components of the sandwich specimen, i.e. face-sheets, foam core and adhesive (face-sheet-core interface) may undergo different internal and external damage in the forms of material failure and geometric deformation. These damage modalities may appear simultaneously and manifest differently in the three constituents: they may manifest as delaminations, face-sheet fractures and residual indentation on the face-sheets; they can appear in the form of foam crushing, residual indentation and cavity formation in the foam core; and emerge as face-sheet-core interface debonding. After the impact, the damage type and extent on the sandwich panels were evaluated by non-destructive inspection (NDI) and sectioning with optical methods.

\section{A. Non-destructive inspection}

For the specimens with permanent indentations after impact (Fig. 4), non-destructive inspections of the damaged panels were processed to assess the damage type and extent induced during the impact. The shape, size and maximum depth of the residual indentation were evaluated using a digital image correlation method by ARAMIS 3D measuring system. Impact damaged specimens were also subjected to Micro-CT scanning (courtesy of the facilities at the Dental school at the Univ. of Michigan) for investigating the damage inside the impacted face-sheets.

\section{B. Sectioning}

For specimens impacted by different energies and impactor sizes, a combination of destructive sectioning and optical method was used to verify the damage state in the cross-sections of the face-sheet and foam core in the damaged area. Square slices big enough to contain all the damaged regions were cut from the impacted panels and immersed in a container with epoxy (to avoid introducing new damage during the cutting). After curing, the slices were cut through the centers of the impacted areas, images were then taken by microscope and scanning electron microscopy (SEM) at different magnifications to investigate the damage in detail. 


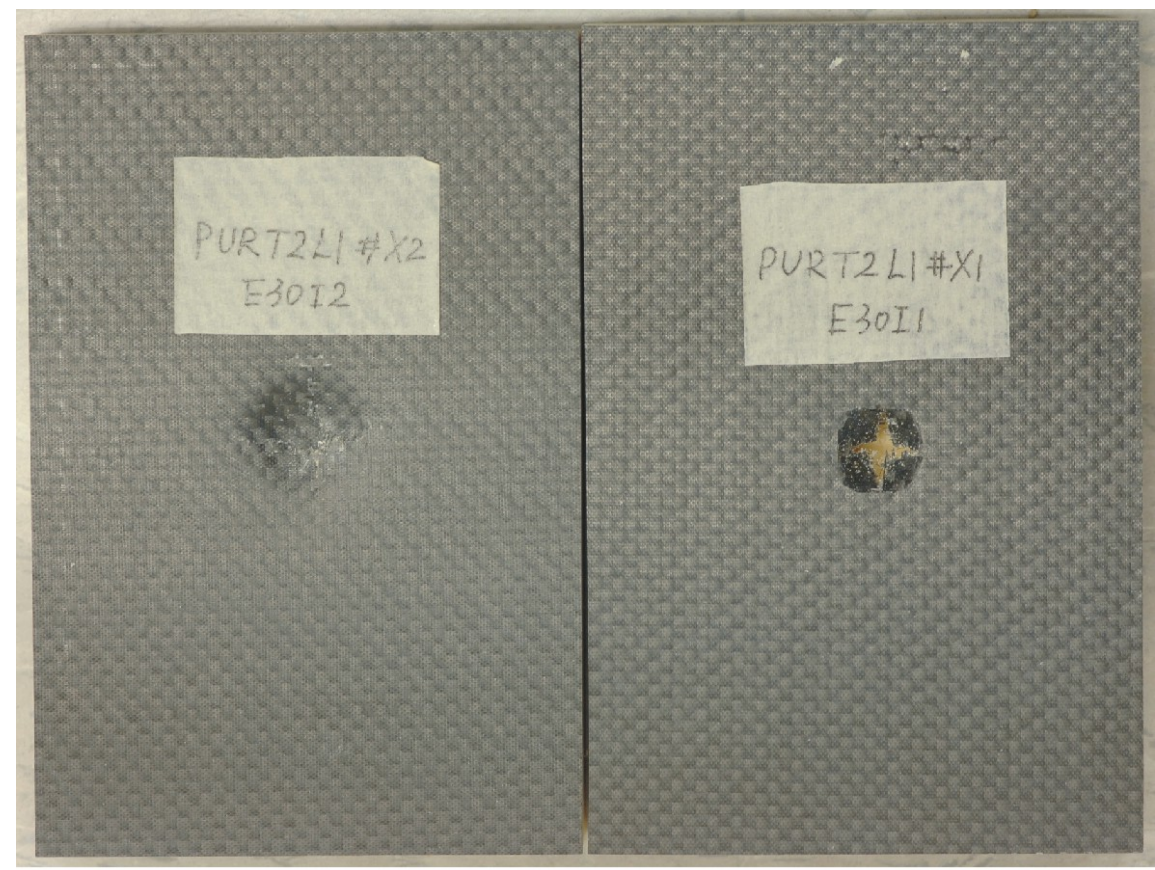

(a)

(b)

Figure 4: Specimens after impact: (a) PURT2L1_E30I2; (b) PURT2L1_E30I1.

\section{Results and discussion}

\section{A. Planar damage and residual indentation}

For the case PUT112_E30I2, Fig. 5(a) and Fig. 5(b) show the 3D profile of the indentation mapped by ARAMIS and detailed damage shapes of plies inside the face-sheet obtained by Micro-CT scan, respectively.

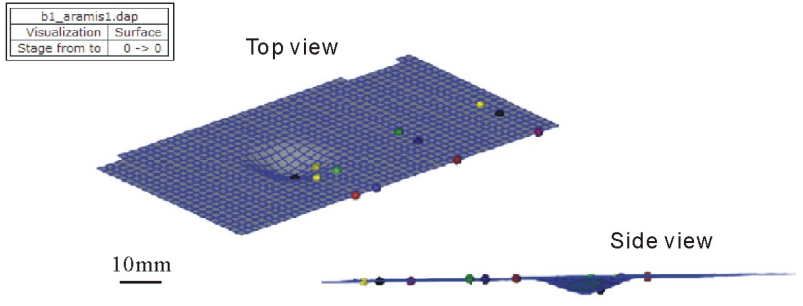

(a)

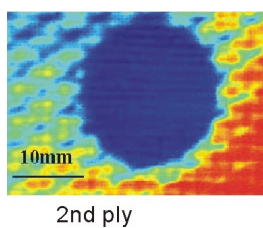

2nd ply

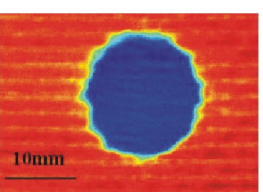

3rd ply

(b)

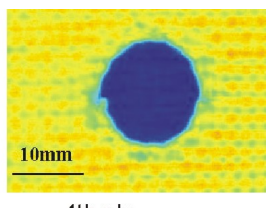

4th ply

Figure 5: NDI for the case of PURT1L1_E30I2: (a) Face-sheet indentation profile mapped by ARAMIS. (b)Micro-CT scan of 2nd, 3rd and 4th plies.

It can be seen from Fig. 5(a), that the planar shape of the damage area in the woven composite laminates is circular, which is different from unidirectional ply composite laminates where a peanut shaped damage is common in the direction of the fibers. This is supported by the Micro-CT scan images which show very similar internal damage profile. The planar damage diameter and indentation depth measured by the 3D ARAMIS are summarized in Table 2.

The Micro-CT scan images display almost the same circular damage at each ply inside the laminate, except that the size decreases slightly from the outer ply to the inner ply, which is mainly due to the semi-spherical shape of the indentation. 
Table 2: Average values of the results for impact tests

\begin{tabular}{cllllll}
\hline Test case & $\begin{array}{l}\text { Peak } \\
\text { load } \\
(\mathrm{kN})\end{array}$ & $\begin{array}{l}\text { Duration } \\
(\mathrm{s})\end{array}$ & $\begin{array}{l}\text { Absorbed } \\
\text { energy } \\
(\mathrm{J})\end{array}$ & $\begin{array}{l}\text { Absorbed } \\
\text { energy } \\
\text { Impact } \\
\text { energy } \\
\text { ratio }\end{array}$ & $\begin{array}{l}\text { Planar } \\
\text { damage } \\
\text { diameter } \\
(\mathrm{mm})\end{array}$ & $\begin{array}{l}\text { Residual } \\
\text { inden- } \\
\text { tation } \\
\text { (mm) }\end{array}$ \\
\hline PURT1L1_E30I1 & 3.91 & 0.0105 & 17.58 & $58.6 \%$ & 18.2 & 5.8 \\
\hline PURT1L1_E30I2 & 5.63 & 0.0081 & 15.38 & $51.3 \%$ & 27.5 & 3.0 \\
\hline PURT1L3_E30I2 & 6.27 & 0.0075 & 13.97 & $46.6 \%$ & 18.1 & 1.9 \\
\hline PURT2L1_E30I1 & 3.84 & 0.0098 & 17.36 & $57.8 \%$ & 17.9 & 5.9 \\
\hline PURT2L1_E30I2 & 6.03 & 0.0075 & 15.72 & $52.4 \%$ & 26.8 & 3.0 \\
\hline PURT2L1_E30I3 & 6.79 & 0.0070 & 14.26 & $47.5 \%$ & 16.8 & 2.0 \\
\hline PURT2L3_E7.5I1 & 3.52 & 0.0073 & 3.83 & $51.1 \%$ & 4.9 & 0.8 \\
\hline PURT2L3_E15I1 & 3.92 & 0.0078 & 8.27 & $55.1 \%$ & 10.6 & 1.2 \\
\hline PURT2L3_E30I1 & 4.95 & 0.0081 & 16.90 & $56.3 \%$ & 17.3 & 3.6 \\
\hline PURT2L3_E30I2 & 6.72 & 0.0070 & 14.02 & $46.7 \%$ & 17.7 & 1.9 \\
\hline
\end{tabular}

B. Sectioning results

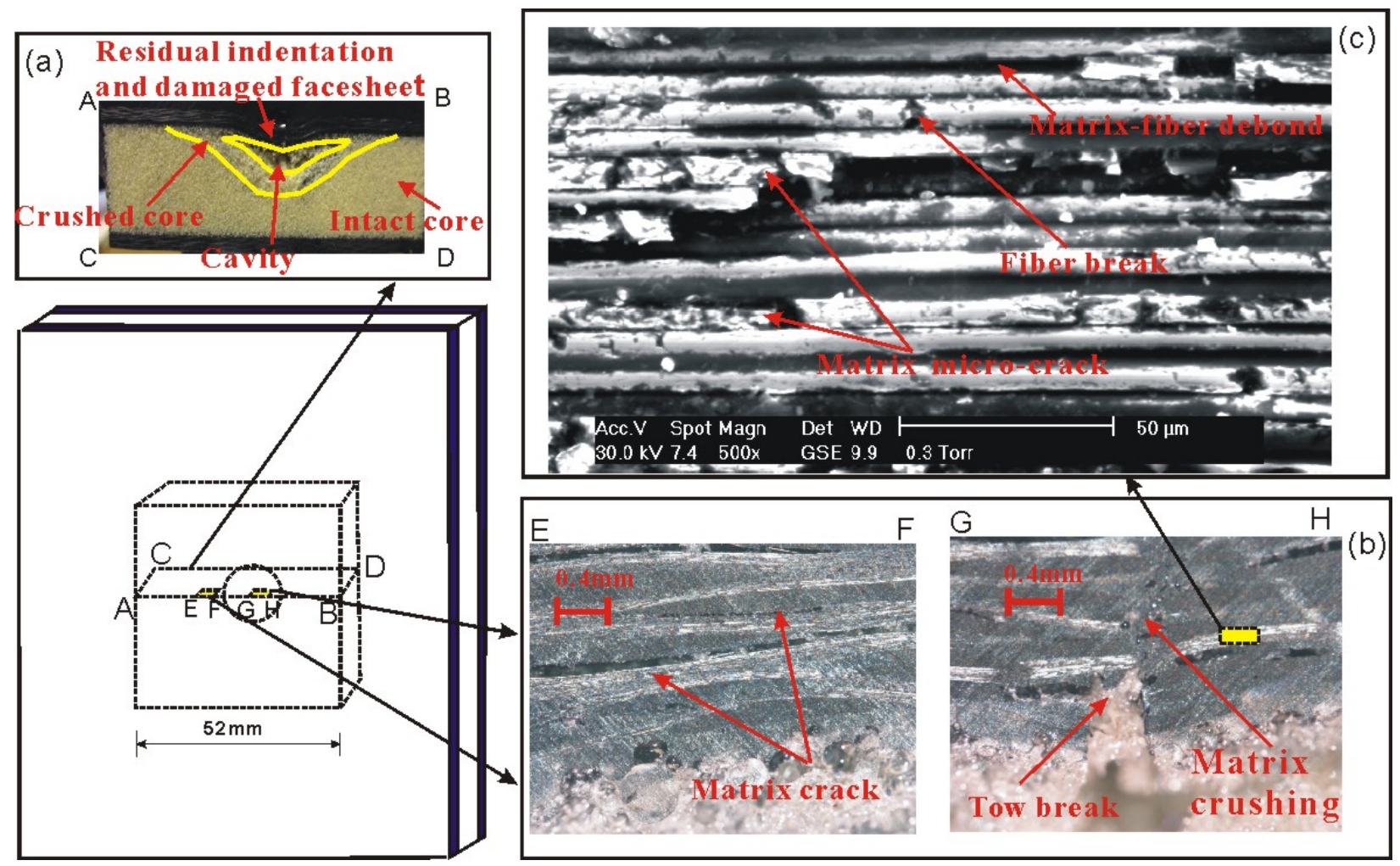

Figure 6: Optical results of sectioning.

For a typical specimen section without penetration (Fig. 6a), indented face-sheet and crushed foam with 


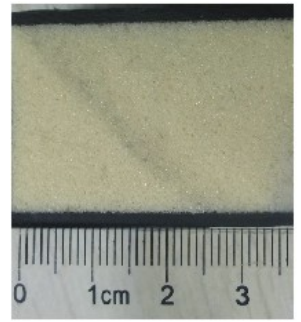

(a)

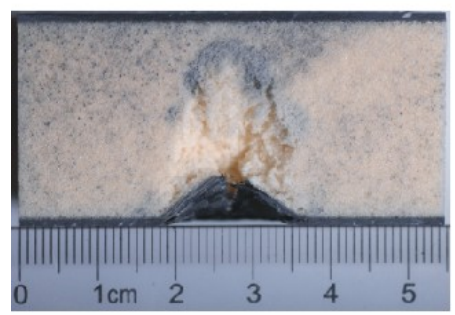

(e)

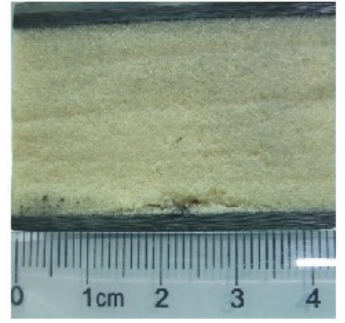

(b)

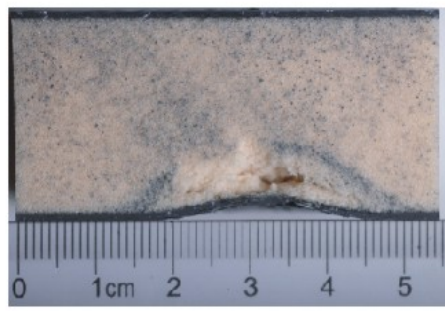

(f)

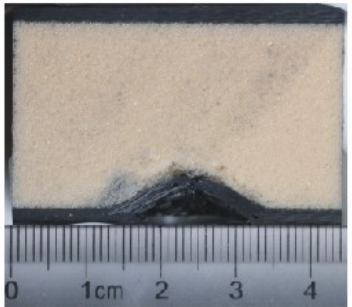

(c)

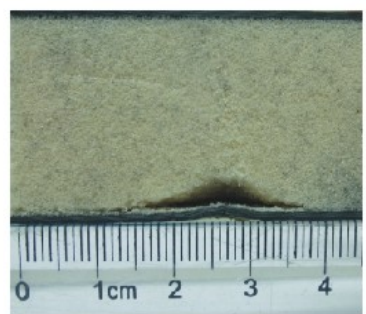

(g)

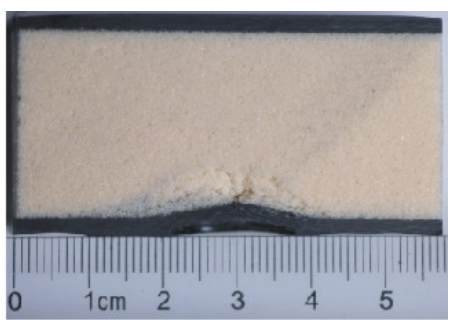

(d)

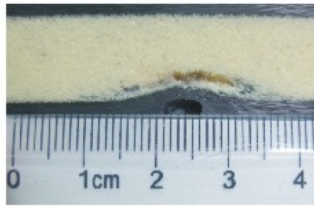

(h)

Figure 7: Sectioning images: (a) PURT2L3_E7.5I1; (b) PURT2L3_E15I1; (c) PURT2L3_E30I1; (d) PURT2L3_E30I2; (e) PURT2L1_E30I1; (f) PURT2L1_E30I2; (g) PURT2L1_E30I3; (h) PURT1L3_E30I2.

cavity right under the impact location can be found by visual inspection. The inter-ply damages modes can be identified through microscope images (Fig. 6b), as follows: matrix crushing due to compression between plies near the top surface, matrix crack between plies near the bottom surface and tow break due to tension in the bottom plies. The SEM image (Fig. 6c) shows the intra-ply damage modes, which are in the form of matrix micro-crack, fiber fracture and matrix-fiber debond inside the fiber tows. Sectioning of damaged sandwich panels for selected cases are shown in Fig. 7.

\section{Impact response}

Fig. 8 presents the contact force history curves for selected cases (Reference to Fig. 3 for the coding). Corresponding contact force-displacement plots are depicted in Fig. 9. The curves were grouped to investigate the effects of impact variables (impact energy and impactor size) and sandwich configuration parameters (face-sheet thickness and foam core thickness) on the impact response and resulting damage state in the sandwich panels. The average values of the impact response are also summarized in Table 2. The impact energy was defined as the total amount of energy introduced to a sandwich specimen. The energy absorbed by the specimens from the impact was calculated from the initial kinetic energy minus the rebound kinetic energy using initial and rebound velocities. This energy was absorbed by the sandwich specimen through the impact event by formation of damage inside specimen, through strain and kinetic energy.

Fig. 8(a) shows that, for the lowest impact energy $(7.5 \mathrm{~J})$, the load-time curve is nearly symmetry with smooth loading and unloading portion. However, for a higher impact energy $(15 \mathrm{~J})$, the curve is no longer smooth, instead, a major load drop occurs and is followed by multiple cycles of loading and partial unloading before the final unloading. When the impact energy goes up to $30 \mathrm{~J}$, there is a sudden, large drop in contact force followed by a short plateau, then the contact force continues to increase nonlinearly until the peak load is reached. As we can see, the peak load increases greatly and contact time increases slightly with the impact energy, while the load at which the major load drop occurs (if there is any) is almost the same for these 3 energy levels.

It can be seen from Fig. 8(b), that impactors with larger diameters induce larger contact force on the test specimen primarily due to larger contact area at the point of contact. The peak load and the load at which the major load drop occurs increase with the impactor size while the contact duration decreases. The shortest duration $(0.0007 \mathrm{~s})$ and highest force $(6.79 \mathrm{kN})$ appear at the case of PURT2L1_E303.

As indicated in Fig. 8(c), both the peak load and the load at which the major load drop occurs increase with face-sheet thickness, while the contact duration decreases.

The contact force history curves show almost the same trend for sandwich panels with two different 


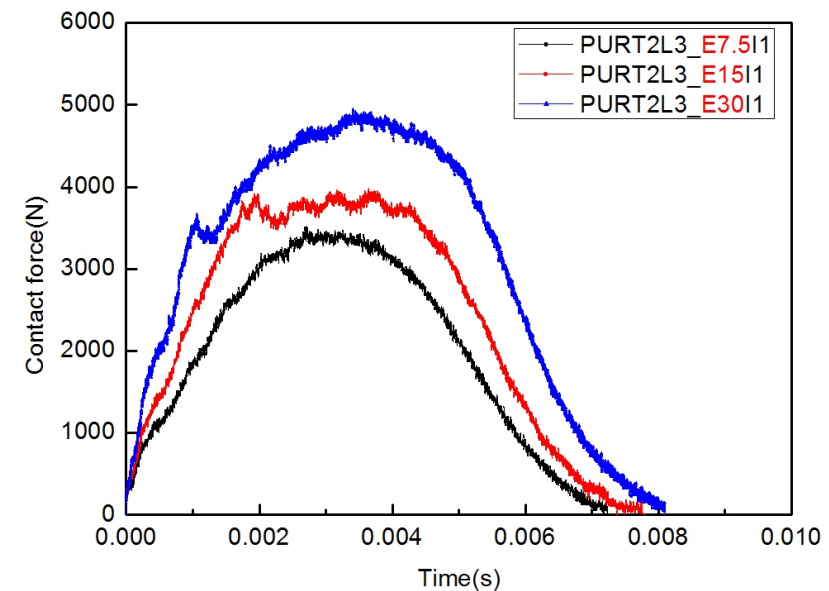

(a)

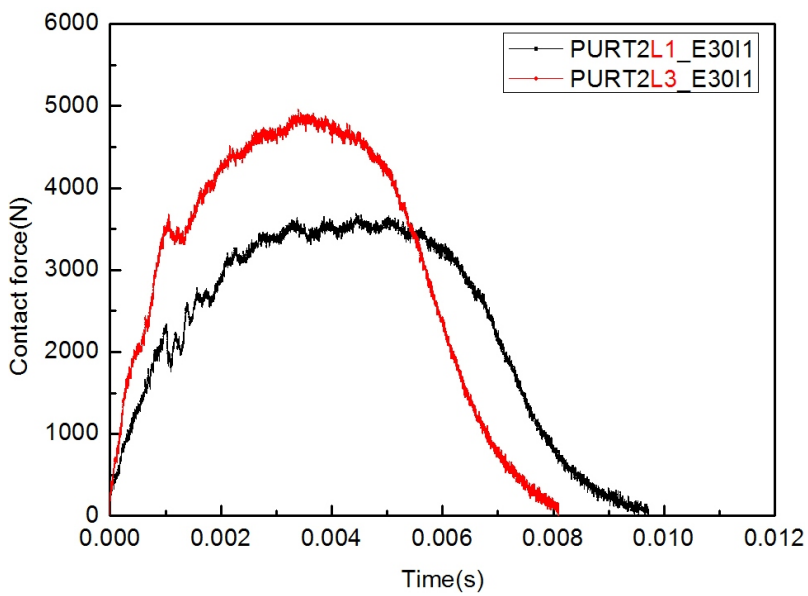

(c)

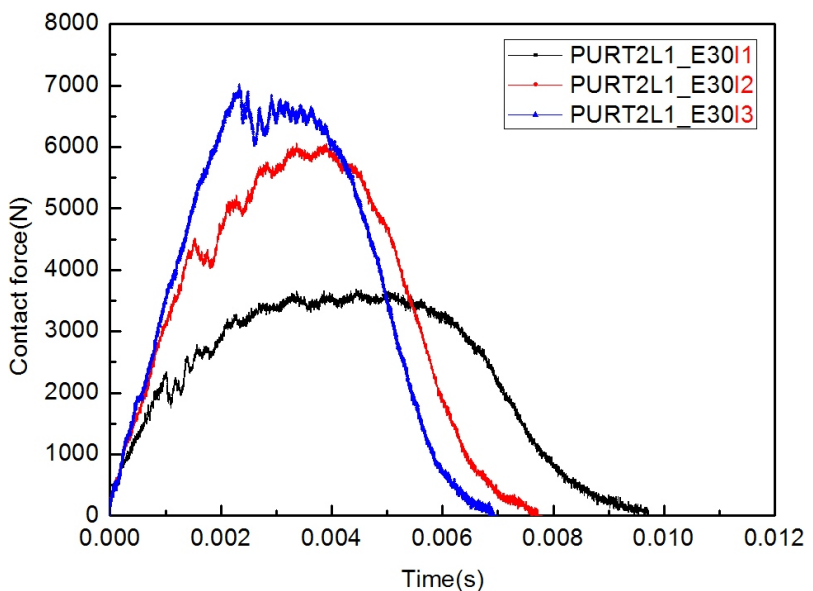

(b)

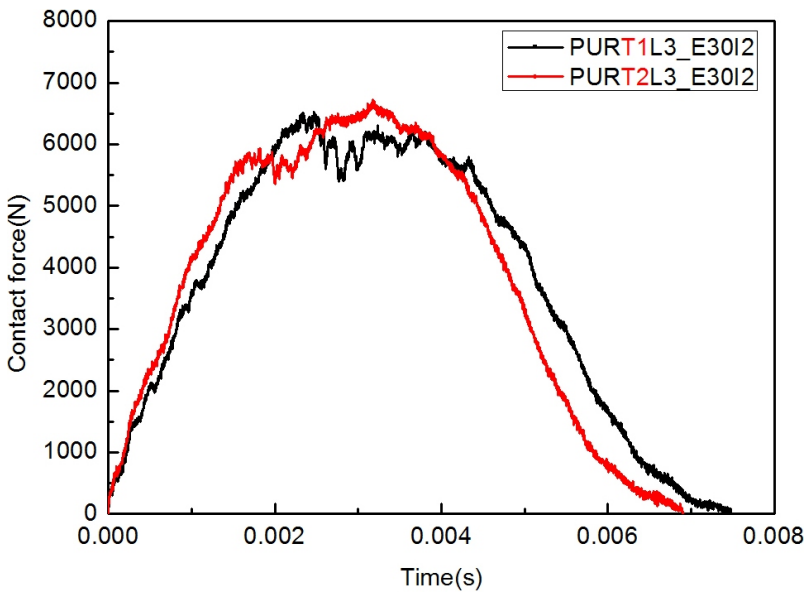

(d)

Figure 8: Contact force history: (a) impact energy effect; (b) impactor size effect; (c) face-sheet thickness effect; (d) foam core thickness effect.

thicknesses, corresponding to $12.5 \mathrm{~mm}$ and $25 \mathrm{~mm}$ (Fig. $8(\mathrm{~d})$ ). This is not surprising: local rigidity, rather than the overall structural rigidity, is much more involved in the impact event. In other words, the impact response of the sandwich panel is independent of the core thickness.

A change in slope of the contact force-impactor displacement curve indicates a stiffness reduction due to damage. And the characteristics of contact force-impactor displacement curves were analyzed with images of damaged specimens to reconstruct the damage process in the sandwich panels during impact events.

Fig. 9(a) shows that there is no load drop in the loading part for the case of PURT2L3_E7.5I1, which indicates there is no damage occurrence in the sandwich panel. A barely visible indentation $(0.8 \mathrm{~mm}$ in depth) on the top surface and almost intact core under the impact location confirm this (Fig. 7a). When the impact energy was increased to $15 \mathrm{~J}$, the contact force-impactor displacement curve consists of an initial linear portion (with slight nonlinearity due to nonlinear geometrical effects) corresponding to a linear elastic behavior until the foam core begin to crush. The crushing of the foam leads to a sudden drop in contact force but not to a catastrophic failure. After initial core failure, the contact force holds at a constant value due to the progressive collapsing of the foam. With the impactor continues drop down, the contact force increases and causes the matrix crack and progressive fiber break in the bottom plies (Fig. 7b), corresponding to a fluctuating slope after the plateau in the plot. For the highest impact energy (30J), a longer fluctuating slope appears after the plateau, which leads to a thicker indentation and more matrix cracks with tow break in the face-sheet accompanied with larger area core crushing under the face-sheet (Fig. 7c). 


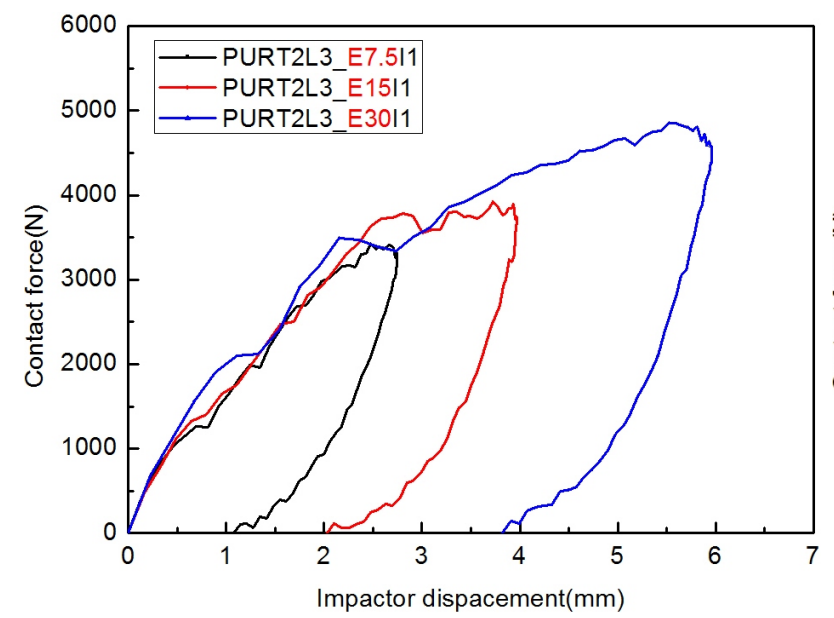

(a)

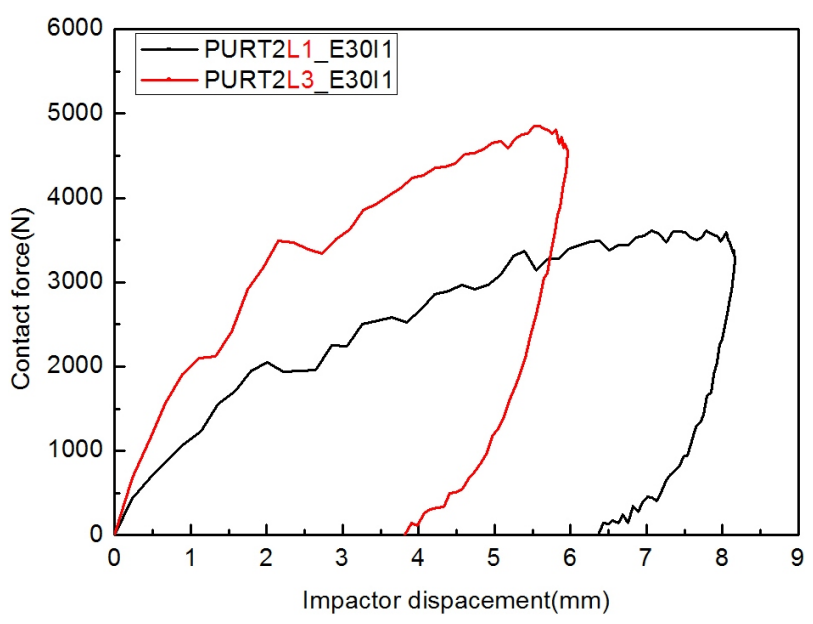

(c)

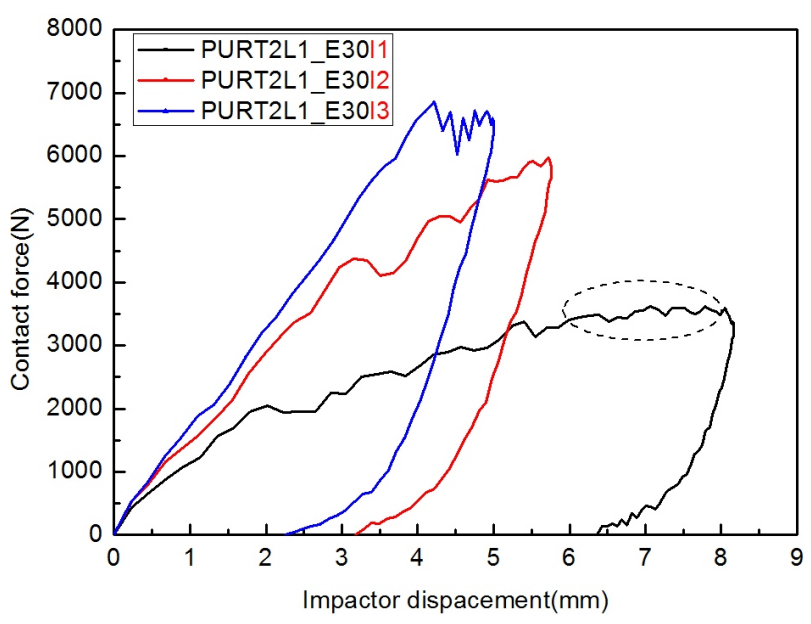

(b)

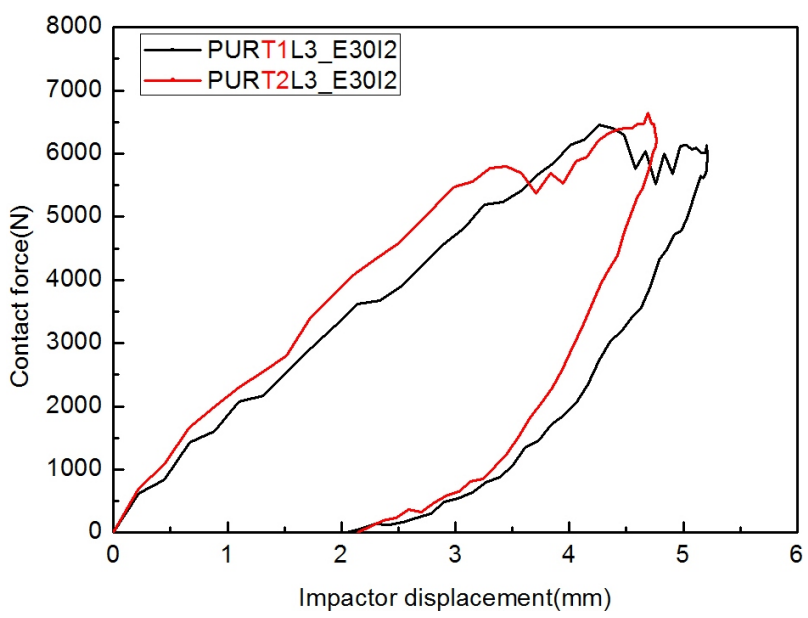

(d)

Figure 9: Contact force-impactor displacement curves: (a) impact energy effect; (b) impactor size effect; (c) face-sheet thickness effect; (d) foam core thickness effect.

As shown in Fig. 9(b), for the smallest impactor case (PURT2L1_E30I1), a sudden load drop appears following the long fluctuating slope, which leads to face-sheet fracture along the perimeter of the impactor. Then the fractured face-sheet plunges into the core and causes large area foam crush under the face-sheet (Fig. 7e), corresponding to a prolonged plateau (dash circled region in Fig. 9(b)) in the contact force-impactor displacement curve. There is no prolonged plateau in the plot when the impactor diameter increases from $15 \mathrm{~mm}$ to $25 \mathrm{~mm}$, and the fluctuating slope is very short when the impactor diameter increases to $35 \mathrm{~mm}$. Besides, the maximum displacement of the impactor decreases with the impactor size. All these trends predict that impactor with smaller diameter $(15 \mathrm{~mm})$ induces much more severer damage in the form of matrix cracks and tow breaks which lead to the occurrence of cross-shaped hole (Fig. 4b) in the face-sheet rather than shallower indentation (Fig. 4a), smaller area foam crush and less tow breaks corresponding to impactors with larger diameters .

Fig. 9(c) shows that for the same impact energy and impactor size, there is no fluctuating plateau appearing in the contact force-impactor displacement plot for case PURT2L3_E30I1 compared to PURT2L1_E30I1. This indicates that the impact causes less damage in the thicker face-sheet (Fig. 7c). This is intuitive, a thicker face-sheet is more damage resistant than a thinner one. As a result, the face-sheet is less deformed and the region of crushed foam is much more smaller compared with the thinner one (Fig. 7e).

The two very similar contact force-impactor displacement curves for cases PURT1L3_E30I1 and PURT2L3_E30I1 
in Fig. 9(d) indicate that the damage process in the sandwich panel is independent of the thickness of the core, and the final damage state are almost the same for the two cases (Fig. 7d and Fig. 7h).

As for the absorbed energy/impact energy ratio of damaged specimens, following trends can be identified from Table 2: it increases with the impact energy and decreases with the impactor size and face-sheet thickness.

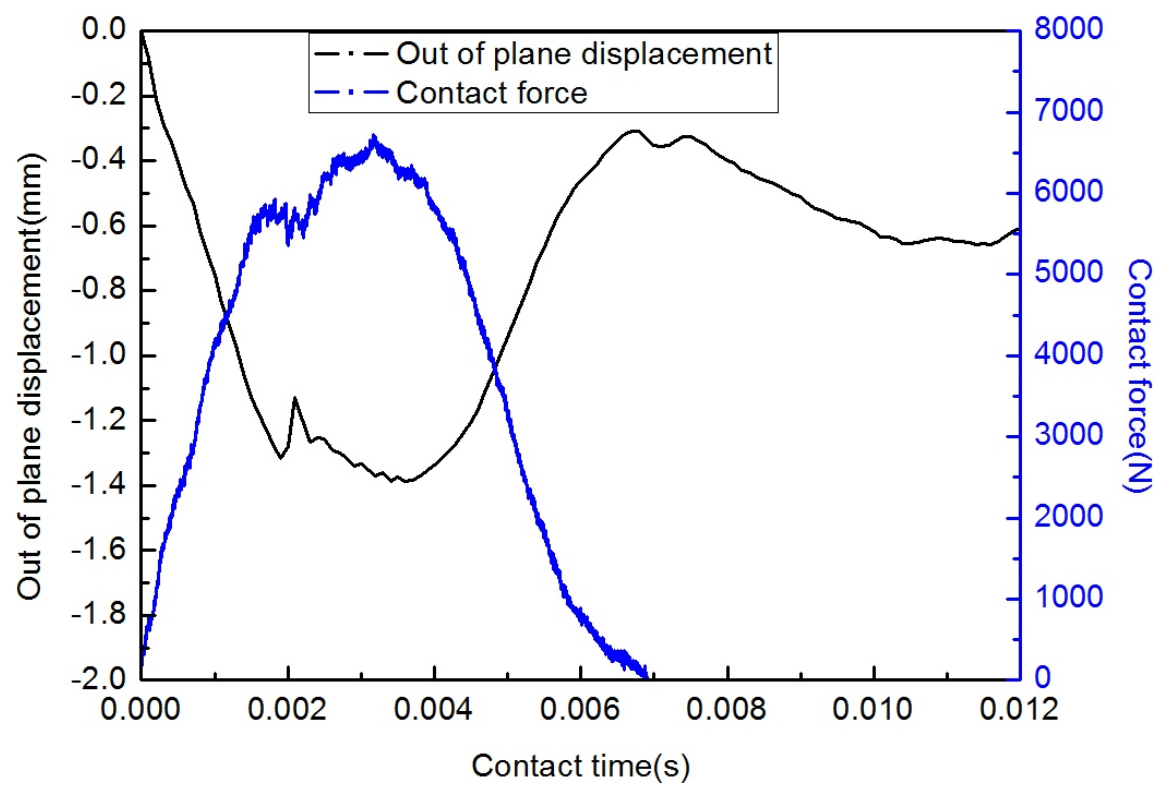

Figure 10: Out-of-plane deformation of the center point at back surface.

The back surface out-of-plane deflection time-history during impact was measured by the 2 high speed cameras in setup 2 with ARAMIS 3D measuring system. Fig. 10 shows the center point out-of-plane deflection time-history and corresponding contact force history for case PURT2L3_E30I2. The out-of-plane deflection is in good correlation with the contact force history. The plot also shows that the panel continues to vibrate elastically after the impact event, but does not return to its initial un-deflected position-i.e. there is a residual deformation, which is about $0.5 \mathrm{~mm}$ for this case. For the severest damage case PURT1L1_E30I1, the maximum residual displacement reaches as high as $1.2 \mathrm{~mm}$. This overall deformation is mainly due to the overall residual bending in the panel caused by through-the-thickness shear plasticity, and is of considerable significance since it will cause a significant reduction in the post-impact compression strength.

\section{Conclusions}

In this study, low-velocity impact tests were carried out on sandwich panels with PUR foam core and plain weave carbon fabric laminated face-sheets. Transient responses of the samples were recorded and analyzed. Digital image correlation, sectioning and optical methods were used to characterize the damage state of the specimens tested. The damage process during the impact event was reconstructed by analyzing the characteristics of contact force-impactor displacement curves and corresponding sectioning images of damaged specimens. The effects of impactor size, impact energy, face-sheet thickness, and core thickness on the impact response and resulting damage states were also studied. From the cases studied, the following conclusions can be drawn:

1) Low-velocity impact can cause the following damage modes in foam-core sandwich panels with plain weave laminates: permanent indentations having semi-spherical shapes under the impactor, matrix crushing due to compression, inter-ply and intra-ply matrix cracks, tow breaks, fiber fracture and fiber-tow debond inside the tows, foam core crushing under the face-sheet and overall residual deformation of the whole panel.

2) The impact parameters, such as peak load, absorbed energy/impact energy ratio and contact duration increase with impact energy; the absorbed energy/impact energy ratio and contact duration decrease with the impactor size, while the peak load increases; the absorbed energy/impact energy ratio and contact duration decrease with the face-sheet thickness, while the peak load increases. 
3) For the most severest damage, the foam core crushes first with the contact force approaching a constant value, then the contact force gradually increases and induces the progressive fiber (tow) breaks and matrix crushing in the face-sheet, a sudden load drop appears corresponding to the face-sheet fracture along the perimeter of the impactor. Thereafter, the fractured face-sheet plunges into the core and causes large area foam crush under the impactor before unloading begins.

4) Both the planar damage diameter and indentation depth increase with the impact energy, while decreasing with the face-sheet thickness.

5) The impact response and damage state are independent of the foam core thickness.

\section{References}

1 Abrate, S., Impact on composite structures, Cambridge University Press, 1998.

2 Zenket, D., The handbook of sandwich construction: 2nd edn, PEMAS Press, 1997.

3 Lie, S. C., "Damage resistance and damage tolerance of thin composite facesheet honeycomb panels," Report 89-3, Massachusetts Institute of Technology, March 1989.

4 Mines, R. A. W., Worrall, C. M., and Gibson, A. G., "Low velocity performation behaviour of polymer composite sandwich panels," International Journal of Impact Engineering, Vol. 32, Nov. 1990, pp. 855879.

5 Bhuiyan, M. A., Hosur, M. V., and Jeelani, S., "Low-velocity impact response of sandwich composites with nanophased foam coreand biaxial45 braided face sheets," Composites: Part B, Vol. 40, No. 6, 2009, pp. $561-571$.

${ }^{6}$ Hosur, M. V., Abdullah, M., and Jeelani, S., "Manufacturing and low-velocity impact characterization of foam filled 3-D integrated core sandwich composites with hybrid face sheets," Composite Structures, Vol. 69, No. 2, 2005, pp. 167-181.

7 Schubel, P. M., Luo, J. J., and Daniel, I. M., "Low velocity impact behavior of composite sandwich panels," Composites: Part A, Vol. 36, No. 10, 2005, pp. 1389-1396.

8 Compston, P., Styles, M., and Kalyanasundaram, S., "Low energy impact damage modes in Aluminum foam and polymer foam," Journal of Sandwich Structures and Materials, Vol. 8, No. 5, 2006, pp. 365-379.

9 Anderson, T. and Madenci, E., "Experimental investigation of low-velocity impact characteristics of sandwich composites," Composite Structures, Vol. 50, No. 3, 2000, pp. 239-247.

10 Nemes, J. A. and Simmonds, K. E., "Low-velocity impact response of foam-core sandwich composites," Journal of Composite Materials, Vol. 26, No. 4, 1992, pp. 500-519.

11 Aktay, L., Johnson, A. F., and Holzapfel, M., "Prediction of impact damage on sandwich composite panels," Computational Materials Science, Vol. 32, No. 3, 2005, pp. 252-260.

12 Nguyen, M. Q., Jacombs, S. S., Thomson, R. S., Hachenberg, D., and Scott, M. L., "Simulation of impact on sandwich structures," Composite Structures, Vol. 67, No. 2, 2005, pp. 217-227.

13 Besant, T., Davies, G. A. O., and Hitchings, D., "Finite element modeling of low velocity impact of composite sandwich panels," Composites: Part A, Vol. 32, No. 9, 2001, pp. 1189-1196.

14 Karger, L., Baaran, J., and Tebmer, J., "Rapid simulation of impacts on composite sandwich panels inducing barely visible damage," Composite Structures, Vol. 79, No. 4, 2007, pp. 527-534.

15 Castanie, B., Bouvet, C., Aminanda, Y., Barrau, J. J., and Thevenet, P., "Modeling of low-energy/lowvelocity impact on Nomex honeycomb sandwich structures with metallic skins," International Journal of Impact Engineering, Vol. 35, No. 7, 2008, pp. 620-634.

16 Aminanda, Y., Castanie, B., Barrau, J. J., and Thevenet, P., "Experimental analysis and modeling of the crushing of honeycomb core," Applied Composite Materials, Vol. 12, No. 3, 2005, pp. 213-227. 
17 Abrate, S., "Modeling of impacts on composite structures," Composite Structures, Vol. 51, No. 2, 2001, pp. 129-138.

18 Hua, Q. Q. and Wang, T., "Low-velocity heavy-mass impact response of slender metal foam core sandwich beam," Composite Structures, Vol. 93, No. 6, 2011, pp. 1526-1537.

19 Fatt, M. S. H. and Park, K. S., "Dynamic models for low-velocity impact damage of composite sandwich panels - Part B: Damage initiation," Composite Structures, Vol. 52, No. 4, 2001, pp. 353-364.

20 Fatt, M. S. H. and Park, K. S., "Dynamic models for low-velocity impact damage of composite sandwich panels - Part A: Deformation," Composite Structures, Vol. 52, No. 3, 2001, pp. 335-351.

21 Etemadi, E., Khatibi, A. A., and Takaffoli, M., "3D finite element simulation of sandwich panels with a functionally graded core subjected to low velocity impact," Composite Structures, Vol. 89, No. 1, 2009, pp. $28-34$.

22 Raju, K. S., Smith, B. L., Tomblin, J. S., Liew, K. H., and Guarddon, J. C., "Impact damage resistance and tolerance of honeycomb core sandwich panels," Journal of Composite Materials, Vol. 42, No. 4, 2008, pp. 385-412.

23 Lascoup, B., Aboura, Z., Khellil, K., and Benzeggagh, M., "Impact response of three-dimensional stitched sandwich composite," Composite Structures, Vol. 92, No. 1, 2010, pp. 347-353.

24 Bernard, M. L. and Lagace, P. A., "Impact resistance of composite sandwich plates," Journal of Reinforced Plastics and Composites, Vol. 8, No. 5, 1989, pp. 432-445.

25 Leijten, J., Bersee, H. E. N., Bergsma, O. K., and Beukers, A., "Experimental study of the low-velocity impact behaviour of primary sandwich structures in aircraft," Composites: Part A, Vol. 40, No. 2, 2009, pp. $164-175$. 